ГРНТИ 06.81.23

DOI: $10.14451 / 1.191 .163$

\title{
ТРАНСФОРМАЦИЯ ПОДХОДОВ К УПРАВЛЕНИЮ ИНТЕЛЛЕКТУАЛЬНЫМ КАПИТАЛОМ ПОД ВЛИЯНИЕМ ЦИФРОВИЗАЦИИ
}

\author{
(c) 2020 Ткаченко Елена Анатольевна \\ доктор экономических наук, профессор \\ Санкт-Петербургский государственный экономический университет, Россия, Санкт-Петербург \\ E-mail: eletkachenko@ya.ru \\ (c) 2020 Рогова Елена Моисеевна \\ доктор экономических наук, профессор декан ШЭМ \\ НИУ Высшая школа экономики в Санкт-Петербурге, Россия, Санкт-Петербург \\ E-mail: elena.rogova@mail.ru \\ (C) 2020 Хуажев Аскер Асланович \\ Санкт-Петербургский государственный экономический университет, Россия, Санкт-Петербург \\ E-mail: askerkhuazhev@mail.ru
}

Актуальность проблемы трансформации интеллектуального капитала методов управления интеллектуальными активами под влиянием цифровых технологий подтверждается исследованием Хаусберга, Дж. П., Liere-Netheler, K., Packmohr, S. et al. (2019), согласно которому количество публикаций по этому вопросу в последние годы превышает 400 статей в год. Цель наших исследований - изучение феномена трансформации интеллектуального капитала на материалах компаний северо-западного региона России и выявление новых моделей интеллектуального капитала, сформированных под влиянием цифровой трансформации. Методика исследования включает в себя собеседования с предпринимателями и топ-менеджерами и статистический анализ результатов исследования для выявления новых параметров функционирования интеллектуального капитала предприятия.

Ключевые слова: интеллектуальный капитал, цифровая трансформация, бизнес-модель

Цифровизация - это структурное изменение для отраслей и основные эффекты цифровизации можно рассматривать как меняющиеся потоки: физические товары изготавливаются и реализуются с применем широкого спектра цифровых услуг; цифровые платформы становятся проще и качественнее; местные услуги приобретают глобальный характер; и таким образом цифровизация позволяет оптимизировать традиционное производство (Бодрунов С. [1]).

Управление знаниями представляет собой направление, в котором ожидается дальнейшее развитие цифровых технологий. В связи с цифровизацией необходимость в изменении бизнес-стратегий и видов деятельности становится очевидной. Это объясняется тем, что цифровые технологии, например Интернет, электронная торговля, электронный обмен данными и электронные конференции, влияют на деловое общение.

Происходящая под воздействием цифровизации трансформация бизнес-процессов вызва- ла существенные изменения в области исследования структуры капитала компаний. Капитал, который большинство исследователей привыкли трактовать в рамках концепции на финансового или промышленного капитала, выделяя также интеллектуальный и человеческий, сейчас представляет собой более сложную структуру. Синтез научных направлений позволил максимально расширить видение экономической категорией «капитал». Авторами статьи «8 форм капитала « Итаном Роландом и Григорием Ландуа [14] в 2011 было определено 8 форм капитала (рис. 1), затрагивающие все сферы человеческой жизнедеятельности, и ими же частично обосновано, как различные типы капитала могут приобретаться, обмениваться и преобразовываться в другие формы. Помимо «классических» форм капитала таких как: «материальный капитал», «финансовый капитал», «интеллектуальный капитал» они выделяют: «социальный капитал» - как влияние и коммуникации в обществе, «эмпирический или человеческий капитал» как сочетание соци- 
ального, интеллектуального капитала и опыта личности, заключенного в человеке, «капитал жизни» как совокупность животных, растений, воды и почвы нашей земли - истинной основы жизни на нашей планете, «культурный капитал» как совокупность внутренних и внешних процессов в рамках сообщества в рамках произведения искусства и традиции, «духовный капитал» как совокупность религии, духовности или других средств обретения связи с собой и вселенной, накопление. он содержит аспекты интеллектуальной и эмпирического капитала, но более глубокие и личные, не поддающиеся количественной оценке.

Л. Эдвинссон в рамках сотрудничества с фирмой Scandia разработал Skandia's value scheme, где составляющими рыночной ценности фирмы назвал финансовый и интеллектуальный капитал (рис. 1), притом финансовый капитал он соотносил с прошлыми достижениями, а интеллектуальный рассматривал как потенциала для будущего роста.

Ключевыми детерминантами интеллектуального капитала являются в этой модели человеческий и структурный капитал.

Свой вклад в эволюцию понимания сущности интеллектуального капитала и разработку моделей управления интеллектуальными активами внесли такие авторы, как Т.Стюарт [18], С. Алберт и К. Бредли [2], С. Асади [3], Дж. Хаусберг [6], Р. Каплан и Д.Нортон [7], Лев Б. [8], М. Манзари [9], Б. Мар [10], Й.Руус, С. Пайк и Л.Фернстем [15] Б. В. Салихов [16], А. Серенко и Н. Бонтис [17]. Обобщенное виденье классических моделей управления интеллектуальным капиталом представлено в трудах М.Р.Мартинес-Торрес [11]. Согласно данному подходу выделяются два этапа моделирования интеллектуального капитала: концептуальное картирование и построение структурных балансовых моделей. При этом ключевыми объектами управления выступают элементы интеллектуального капитала.

Цифровизация - что изменилось?

Преимущества цифровых технологий многочисленны, но их можно разделить на три категории: оптимизация процессов; доступ и процессы сравнения данных могут быть выполнены быстрее; возможность более гибких рабочих процедур. Цифровые и компьютеризированные инструменты, применяемые для работы с информационными ресурсами, обеспечивают следующие преимущества:

- Система управления интеллектуальным капиталом становится автоматизированной;

- в деталях и цифрах;

- обеспечивает удобный доступ к данным;

- повышается безопасность и снижаются риски утраты информации благодаря использованию облачных хранилищ;

- оптимизируются временные затраты и стоимость обслуживания системы;

- упрощается масштабируемость инновационных решений и технологий.

B процессе построения интеллектуальной самообучающейся системы управления знаниями компании не должны сосредотачиваться только на нескольких стратегиях, операционных моделях, маркетинге или технологиях. Наибольшего успеха добиваются те компании, которые готовы сделать тотальную цифровизацию культурной нормой. Как показывают исследования в области технологических сдвигов и изменения технологических парадигм (К.Перес [13], С Глазьев [5] и др.) в настоящее время наблюда-

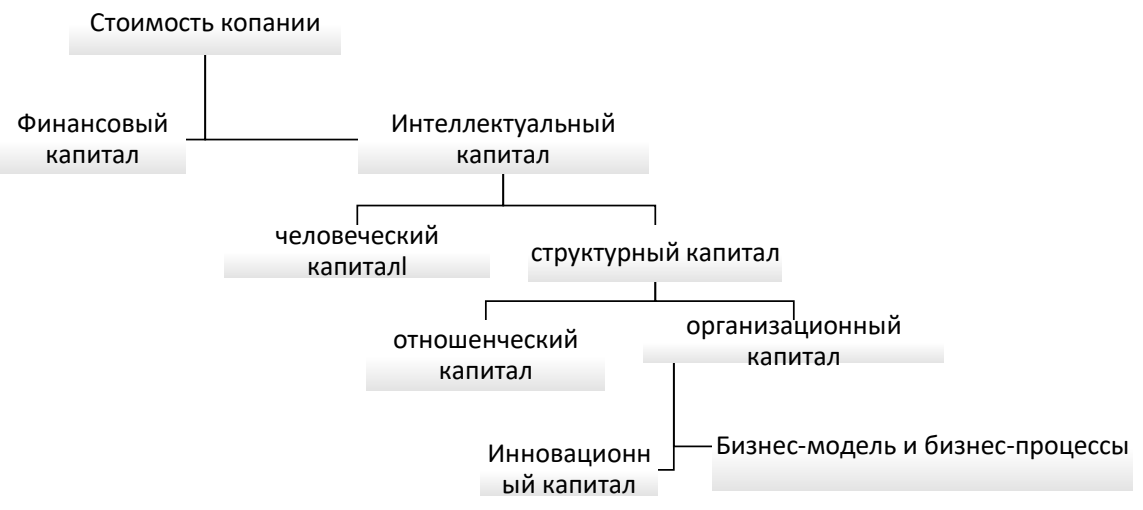

Puc. 1. Структура интеллектуального капитала в модели «Skandia Value Scheme» [4] 
ется экспоненциальный рост темпов и развития технологических сдвигов. В последние несколько лет произошла технологическая революция с ростом цифровых рынков. Этот сдвиг привел к тому, что многие компании изменили фокус бизнеса с аналогового на цифровой. Так же наиболее распространенной причиной для оцифровки бизнеса можно также считать сокращение затрат. Это делается путем автоматизации многих процессов в бизнесе и снижает потребность рабочей силе и, соответственно, приводит к ускорению ключевых процессов.

Чтобы выявить взаимосвязь между типом модели управления знаниями и финансовыми показателями компаний, мы провели опрос топ-менеджеров предприятий Санкт-Петербурга и Ленинградской области с января 2018 года по ноябрь 2019 года. Мы выбрали отрасли с высоким уровнем инновационной деятельности, потому что это сектора, где предприятия, как правило, инвестируют в нематериальные активы, включая технологии, исследования и разработки, человеческий капитал, бренды и т.д. Мы также рассмотрели вопрос о том, существует ли в компании система управления интеллектуальным капиталом или, по крайней мере, ее элементы. Первичная выборка содержала топ-менеджеров 123 компаний.

На первом этапе выяснилось, что от 123 компаний, сформировавших выборку, 31 частные компании подтвердили заинтересованность в управлении ИК и положительно ответили на вопрос о внедрении в своей практике методов управления интеллектуальным капиталом. Мы включили их в выборку для второго этапа исследования. Все выбранные компании также используют технологии цифровых данных, что было важно для целей наших исследований. На втором этапе мы намеревались раскрыть взаимосвязь между типом модели управления знаниями и финансовыми показателями компаний. Мы предоставили нашим респондентам возможность провести качественную оценку типа модели управления знаниями и динамики финансовых показателей, поскольку на предыду- щем этапе они с нетерпением не предоставили количественную дату.

Респондентам было предложено указать, как они будут оценивать инвестиции в следующие статьи интеллектуального капитала за предыдущие пять лет:

1 Интранет-тип модели управления интеллектуальным капиталом

2 Экстранет-тип модели управления интеллектуальным капиталом

3 Интернет-Тип модели управления интеллектуальным капиталом. Предложенные ответы были преобразованы в точки от 0 до 3, как показано в таблице 1.

Для оценки эффективности стоимости мы попросили респондентов высказать свое мнение о финансовой стабильности своих предприятий и предложили следующие ответы:

0 баллов - стоимость компаний снизилась

1 балл - стоимость компаний осталась неизменной

2-5 пунктов - стоимость компаний выросла.

Мы проверили 2 гипотезы во время процесса регрессионного анализа.

Гипотеза 1: Модель управления интеллектуальным капиталом на принципах Интранет будет оказывать более сильное влияние на финансовые показатели благодаря лучшей защите данных. Результаты представлены в таблице 2.

Как следует из регрессионной модели, R-квадрат равен 0,792, что указывает на высокую взаимосвязь между стоимостью компании и использованием цифровых моделей для управления знаниями. Но фактор X1 - тип интрасети - не был статистически значимым и должен быть исключен из дальнейшего анализа, что опровергает Н1 гипотезу о более высоком влиянии моделей типа интранет на результаты деятельности компании.

Гипотеза 2: Существует взаимосвязь между типом цифровой модели управления Интеллектуальным капиталом и изменением стоимости компании. Результаты представлены в таблице 3, где зависимая переменная обозначает изменение значения.

Таблица 1: Предлагаемые ответы, преобразованные количественные результаты

\begin{tabular}{|l|c|c|}
\hline \multicolumn{1}{|c|}{ Тип модели } & $\begin{array}{c}\text { Не используется или в стадии } \\
\text { становления }\end{array}$ & Модель используется более 2 лет \\
\hline Интранет & 0 & 1 \\
\hline Экстранет & 0 & 2 \\
\hline Интернет & 0 & 3 \\
\hline
\end{tabular}


Таблиц̧а 2. Регрессия-1

\begin{tabular}{|c|c|c|c|c|c|c|}
\hline \multicolumn{2}{|c|}{ Regression statistics } & & & & & \\
\hline Multiple R & 0,890069 & & & & & \\
\hline R-squared & 0,792223 & & & & & \\
\hline $\begin{array}{l}\text { Adjusted } \\
\text { R-squared }\end{array}$ & 0,769136 & & & & & \\
\hline Std. Error & 0,504673 & & & & & \\
\hline \multirow[t]{2}{*}{ Observations } & 31 & & & & & \\
\hline & Coefficients & Standard error & $t$-statistics & $P$-Value & Lower 95.0\% & Upper $95.0 \%$ \\
\hline $\mathrm{Y}$ - intersection & 0,096436 & 0,197639 & 0,487939 & 0,629532 & $-0,30909$ & 0,501958 \\
\hline X 1 - Intranet & 0,14325 & 0,101224 & 1,415177 & 0,168448 & $-0,06444$ & 0,350943 \\
\hline X 2 - Extranet, & 0,382394 & 0,111027 & 3,444156 & 0,001885 & 0,154586 & 0,610203 \\
\hline X 3 - Internet & 0,643316 & 0,12205 & 5,270917 & $1,47 \mathrm{E}-05$ & 0,39289 & 0,893742 \\
\hline
\end{tabular}

Таблица 3. Вторая регрессионная модель

\begin{tabular}{|c|c|c|c|c|c|c|}
\hline \multicolumn{2}{|c|}{ Regression statistics } & & & & & \\
\hline Multiple R & 0,881369 & & & & & \\
\hline R-squared & 0,776811 & & & & & \\
\hline Adjusted R-squared & 0,760869 & & & & & \\
\hline Std. Error & 0,51363 & & & & & \\
\hline \multirow[t]{2}{*}{ Observations } & 31 & & & & & \\
\hline & Coefficients & $\begin{array}{c}\text { Standard } \\
\text { error }\end{array}$ & $t$-statistics & P-Value & Lower $95.0 \%$ & Upper $95.0 \%$ \\
\hline $\mathrm{Y}$ - intersection & 0,247412 & 0,169325 & 1,461166 & 0,155102 & $-0,09943$ & 0,59426 \\
\hline X 2-Extranet & 0,464968 & 0,096135 & 4,836612 & $4,34 \mathrm{E}-05$ & 0,268044 & 0,661892 \\
\hline X 3-Internet & 0,631668 & 0,123933 & 5,096832 & $2,13 \mathrm{E}-05$ & 0,377802 & 0,885534 \\
\hline
\end{tabular}

Вторая регрессионная модель соответствует всем критериям, полученные коэффициенты статистически значимы. Уравнение регрессии: $\mathrm{Y}=0,464968 \mathrm{X} 2+0,631668 \mathrm{X} 3$. R-квадрат равен 0,77 . Так, была подтверждена гипотеза 2 о существовании взаимосвязи между использованием открытых цифровых моделей управления интеллектуальным капиталом и ростом стоимости компании. При этом роль моделей, основанных на формировании интернет-платформ, оказалась наиболее значимой с точки зрения финансовых показателей, что требует дальнейших исследований.

\section{Заключение}

Проведенное исследование трансформации моделей управления знаниями в эпоху тотальной цифровизации показало, что наибольший вклад в эффективность и стратегическую устой- чивость компаний вносит создание Интернеториентированных цифровых платформ, приставляющих собой площадку дл взаимодействия и сотрудничества на базе открытых инноваций. Многие компании не могут себе позволить полноценное использование данного направления развития, и вынуждены ограничить себя интранетом и в редких случаях экстранентом, поскольку не имеют возможности выйти на открытые площадки в силу государственной или военной тайны. Дальнейшие наши исследования будут направлены на исследование эффективности проектов миграции систем управления знаниями на облачные сервисы и выбор адекватного математического аппарата для оценки эффективности цифровой трансформации системы управления знаниями. Статья подготовлена при поддержке Гранта Института Нового индустриального развития им. С. Ю.Витте. 


\section{Библиографический список}

1. Бодрунов С.Д. Ноономика. Монография. М.: Культурная революция, 2018

2. Albert S. and Bradley K (1997)., Managing Knowledge: Experts, Agencies and Organizations (Cambridge: Cambridge University Press, 1997).

3. Asadi S. (2013) Intellectual capital knowledge management: organizational value creation//European Online Journal of Natural and Social Sciences 2013; vol.2, No.3 (s), pp. 462-476 URL: european-science.com>eojnss/ article/download/427/

4. Edvinsson L (1997), Developing intellectual capital at Skandia, Long Range Planning, Volume 30, Issue 3, 1997, Pages 366-373,

5. Glazyev S. (2017) The Great Digital Revolution: Challenges and Prospects for the Economy of the XXI https:// glazev.ru/articles/6-jekonomika/54923-velikaja-tsifrovaja-revoljutsija-vyzovy-i-perspektivy-dlja-jekonomiki-iveka

6. Hausberg, J P and Liere-Netheler, K. and Packmohr, S. and Pakura, S. and Vogelsang, K.,(2019) Research Streams on Digital Transformation from a Holistic Business Perspective: A Systematic Literature Review and Citation Network Analysis (November 08, 2019). Journal of Business Economics, vol. 89, p. 931-963, 2019

7. Kaplan R.S., Norton D.P. (1992)The Balanced Scorecard - Measures then drive Performance // Harvard Business Review. - 1992.- Vol. 70.- N 1.- P. 71-79. Foray D.(1999) CRIS, a cost or an investment? Models of innovation in the information age //CRIS 98 Conference. - Luxembourg, 1999

8. Lev, B. (2001) Intangibles: Management, Measurement and Reporting. Washington, DC, Brookings Institution Press.

9. Manzari M., Kazemi M., Nazemi Sh. and Pooya A. (2012) Intellectual capital: Concepts, components and indicators: A literature review// Management Science Letters 2 (2012) 2255-2270 URL: http://www.growingscience.com/msl/ Vol2/msl_2012_185.pdf

10. Marr, B., Schiuma, G. and Neely, A. (2003), "Intellectual capital: defining key performance indicators for organizational knowledge assets”, Business Process Management Journal, Vol. 10 No. 4.Nermien Al-Ali (2013). Comprehensive intellectual capital management. - New Jersey, John Wiley \& Sons, Inc,2003.-295c. www.itworkss. com

11. Martínez-Torres, M.Rocío. (2006) "A procedure to design a structural and measurement model of Intellectual Capital: An exploratory study.” Inf. Manag. 43 (2006): 617-626.

12. Perez C. (2009) Technological revolutions and techno-economic paradigms.: in Working Papers in Technology Governance and Economic Dynamics, Working Paper No. 20, Tallinn: Norway and Tallinn University of Technology, Tallinn 2009.

13. Perez C.(2002) Technological Revolutions and Financial Capital: The Dynamics of Bubbles and Golden Ages. London: Elgar 2002. (ISBN 1-84376-331-1)

14. Roland E. \& Landua G., Regenerative Enterprise, Optimizing for Multi-Capital Abundance (2013). http:// www.8forms.org/8-forms-of-capital/

15. Roos, G., Pike, S. and Fernstrom, L. (2005) Managing Intellectual Capital in Practice, Elsevier ButterworthHeinemann, Burlington, MA.

16. Salikhov B.V. (2009). Economics of Knowledge and system integration model of the company's human capita. Available at: http://bv-salikhov.ru/kognitiv naya-ekonomika.html /

17. Serenko A. and Bontis N.(2004) Meta-Review of Knowledge Management and Intellectual Capital Literature: Citation Impact and Research Productivity Ranking/ Knowledge and Process Management Volume 11 № 3 pp 185-198 (2004). Published online in Wiley InterScience (www.interscience.wiley.com).

18. Stewart T., (1994) Your company’smost valuable asset: intellectual capital, Fortune 130(7) October, 28-33 